\title{
The roles of humour and laughter in youth focus groups on school food
}

\section{Janhonen, Kristiina}

2017

Janhonen, K 2017 , ' The roles of humour and laughter in youth focus groups on school food ' , Journal of youth studies , vol. 20 , no. 9 , pp. 1127-1142 . https://doi.org/10.1080/13676261.2017.1311404

http://hdl.handle.net/10138/309845

https://doi.org/10.1080/13676261.2017.1311404

unspecified

acceptedVersion

Downloaded from Helda, University of Helsinki institutional repository.

This is an electronic reprint of the original article.

This reprint may differ from the original in pagination and typographic detail.

Please cite the original version. 


\section{The Roles of Humour and Laughter in Youth Focus Groups on School Food}

The article examines young people's group interaction and the roles of humour and laughter in relation to school food and school lunch situations. The analysed focus group discussion data is drawn from a broader case study (2012-2013) with 9th grade students (15-16 years old; 62 pupils; 25 boys and 37 girls; 14 groups; 4-6 pupils per group) in a Finnish secondary school. The analysis is based on existing interpretations and classifications of humour in literature, which is complemented by notions drawn from the study's data set. It is argued that an analysis of humour and laughter can provide valuable notions of how collective attitudes towards school food are constructed, enforced and distributed among students, while also providing insight regarding what kinds of issues around school lunch practices are considered important and worthwhile in the context of students' informal peer cultures. The results illustrate how humour and laughter functioned for the students as a space for 1) Constructing 'us' versus 'them'; 2) Negotiating social order; and 3) Engaging in fun and safe interaction. Results are discussed in the light of how humour and laughter uphold or divide social groups, as well mediate shifts between formal conventions and students' informal worlds.

Keywords: humour; laughter; school food; school lunch situations; youth

\section{Introduction}

Humour and laughter are important parts of being human and interacting with one another. The study of humour has fascinated scholars and philosophers for centuries (Atkinson 1993; Virtanen 2003; Watson 2015). The extensive prior literature on the role of humour in social interaction has demonstrated that an analysis of these elements can reveal a great deal about values and norms in a specific culture and society (e.g. Billig, 2005). However, because of their inevitably context-bound and subjective nature, interpreting humour or laughter is not a simple endeavour (e.g. Meyer, 2000). All people simply do not laugh at the same things, nor does laughter always indicate the 
appearance of humour (Ibid.)

Despite the ambiguous nature of humour in social interaction, an analysis of the role of its forms, such as irony, sarcasm and witty remarks, can provide valuable knowledge of the background motives of research participants and of individuals' own interpretations of their actions in relation to surrounding social structures, such as the school as an institution (Valve and Pelkonen 2013; Watson 2015). Research on humour and laughter can further provide an interesting and multifaceted window to the study of young people's interaction and peer cultures. As Hokkanen (2014) has emphasized, an exploration of young people's use of humour can provide an opportunity to deliberate on what young people's own cultures might be like, rather than adopting an approach that interprets young people's behaviour through values or aims set by adults. Although the field of youth studies contains abundant research on youth cultures and related phenomena, studies with a specific focus on young people and food are less prominent (Bahr Bugge 2010). To fill this gap, this article takes young people's ways of discussing about and reacting to issues around school food as a way to gain deeper understanding of the dynamics of their social life and of the values and motivations underlying their food practices. While this theme bears relevance to both youth research and education alike, knowledge of the forms and roles of humour and laughter and their connections to attitudes towards school lunches remain, until now, a largely understudied phenomenon.

The study is positioned in the Finnish secondary school context, in which the provision of hot and tax-paid school lunches has been a part of health promotion for over sixty years, and in which the educational purposes of school lunches are stated in the National Curriculum (Finnish National Board of Education [FNBE] 2014; Perusopetuksen Opetussuunnitelman Perusteet [POPS] 2014) [1]. Prior research conducted in the Nordic context has shown that school lunch criticism is a collective 
norm not only among young people, but also often among parents (e.g. PerssonOsowski 2012). Children also tend to speak about school lunches in a negative way even if they do not actually dislike the food (Ibid.). This is in line with results from earlier stages of the present study (Author et al., 2016), which show that some students see talking negatively about school lunches as something that spreads easily among students and that can even became an unconscious way of thinking about school food. One explanation for this might be the tendency of young people to avoid social exclusion (Korkiamäki 2011; Palmqvist and Santavirta 2006). In fact, the desire to belong has been shown to override even personal preferences among young people (Neely et al. 2014). However, there is a need for research on how this plays out in practice.

\section{Young People and Humour at School}

Humour plays a central role in young people's lives (Herkman 2001). Nonetheless, the use of humour at school is a controversial and ambiguous topic, not only from a pedagogical perspective, but also as a substance of young people's informal worlds (Herkman 2001; Hokkanen 2014). This is at least partly due to the fact that humour often includes aspects that might threaten the credibility or validity of people or practices. According to Watson (2015), these effects might arise from the potential hostility and unethicality of humour as well as its unserious and sometimes irresponsible tenets (Watson 2015). Importantly, humour always also includes the use of power: who has the power to laugh, who or what is laughed at and what is the nature of the laughter (Herkman 2001). For example, humour can undermine and challenge authority or function as a way to support and reward socially approved behaviour. On the other hand, humour can also enable young people to build group coherence in a 
positive way by allowing a sense of sociality, reciprocity and belonging (Ibid). From young people's perspectives, humour can help in coping with challenging social situations or serve as protection under sensitive or risky circumstances (Cameron et al. 2010). In this way, humour can also function as emotional currency or as a social safe zone.

Although humour is often considered to be light and fun, it is rarely senseless or irrational (Virtanen 2003). As Virtanen (2003) stated, using humour almost invariably requires insight, wit, contextual knowledge and the ability to creatively combine different themes and topics. Since a commitment to the hidden values of a joke is not an absolute prerequisite for telling it, humour can also be used as a leeway to express strong statements, and it can provide opportunities for young people to disrupt existing power relations or inequalities (Ibid.). As Hokkanen (2014) observes, humour can provide a way for young people to create a new reality — their own space - through breaking existing rules and taboos. An analysis of young people's interactions including humour and laughter can therefore also provide knowledge about their understandings of appropriate behaviour and values and their attitudes towards institutional norms.

\section{Humour as an Analytical Framework}

Humour can be defined as a special way of communicating (Sørensen, 2015), or indeed, any message intended to produce a smile or a laugh. Notably, humour is not in itself either good or bad: it can be used for making people happy or to hurt them (Billig, 2005; Sciama, 2016). Humour can also function as either a social unifier or a divider, thus, simultaneously both strengthening social coherence and highlighting social boundaries (Meyer, 2000). 
From a theoretical perspective, humour is habitually interpreted based on the following three models: the superiority theory that can be traced back to Hobbes (1670) and Bergson (1899); the incongruity theories leaning on, for example, Kant (1982) and Schopenhauer (1909); and the relief theories drawing from the work of Freud (1905; 1981) and perhaps also Aristotle (see Atkinson 1993). Virtanen (2003) states that although other classifications exist (along with differences in placing theoreticians or philosophers within these theories), this three-fold classification dates back at least to the beginning of the 1980s, and it is currently broadly known and used among researchers of humour. Notably, these three models should not be considered as exclusive, but as partly overlapping and complementary (Ibid.). Examined in conjunction, the classification enables a broad-ranging interpretation of the roles of humour in young people's interaction. More specifically, the superiority theory enables an examination of instances in which humour is found in the misfortune of others; the relief theory posits that people laugh because they feel that stress has been reduced in a certain way; and the incongruity theory focuses on the ways that instances clash with existing ideas of how things should be or function (Watson 2015).

In the present article, these classifications and interpretations of humour will be used as a starting point for examining episodes including laughter in young people's school food-related group interaction. However, as Meyer (2000) points out, the threefold classification of humour does not necessary succeed in capturing humour's effects. Therefore, in order to grasp the situationally dependant nature of humour interpretations, it is important to acknowledge also the intended audiences and the dynamics of interaction that follow humorous behaviour. As a focus of research, then, the interrelationship between humour and laughter includes the opportunity to examine the ways in which social relations are enforced and/or dismantled in an institutional 
context. Since humour can also be used as a means to include or exclude, to distance or to bring someone closer (Hokkanen 2014; Meyer, 2000; Virtanen 2003), an analysis of its forms can shed light on the ways that social categories are constructed or resisted.

In this study, the core interest is to examine young people's group interaction in relation to school food and school lunch situations. The examination focuses on spontaneous and situation-specific humour. Leaning on Virtanen's (2003) definition, situation-specific humour is defined as including irony, sarcasm and witty remarks. Although even in its planned form humour is highly disposable by nature, the momentarity and contextuality of it is even further emphasized in spontaneous joking and situation-specific quips. However, humorous interaction is always also connected to a metalanguage which is constructed from the deeper meanings that are imbued in the use of humour (Virtanen 2003). Below, these meaning structures and roles are examined in young people's group interaction in relation to school food and school lunch situations.

\section{Methods and Data}

The article draws from a broader case study (2012-2013) on young people's school food practices conducted among the $9^{\text {th }}$ grade students $(15-16$-year-olds) of one Finnish secondary school (Author et al. 2016). The focus of the data collection was on the informal school, that is, the everyday cultures and the informal discussions and interaction between pupils or between pupils and teachers (e.g. Gordon et al. 1999). In accordance with the new social studies of childhood (Corsaro, 2005), adolescents in this study are seen as active agents contributing to societal change and not only passively appropriating influences from their surroundings. 
The data analysed in this article include focus group discussions conducted with 62 students ( 25 boys and 37 girls; 14 groups; $4-6$ pupils per group). There were altogether 71 ninth graders in the study school, of which 9 students were not present or could not for other practical reasons be reached at the time of conducting the focus group discussions. The groups were divided into girls and boys and according to classes. The group compilation was based on prior observations during the field period, and followed those groups in which the pupils typically spent their time during the school day. The focus group discussions marked the end of the data collection for the broader case study, and took place in April 2013.

The focus group discussion outline included the following four main themes: 'school lunches', 'school lunch situations', 'influence of friends', and 'rules and making a difference' (see Table 1 for the specific questions).

\section{(TABLE 1 HERE)}

The discussions took place in a calm classroom space habitually used for group work. The order of the questions varied flexibly between groups and all initiatives of the adolescents were encouraged. Drawings produced by the students in earlier stages of the study were used as activating material during the discussions. The length of the discussions varied from 20 to 40 minutes, which illustrates the differences between the temperaments of the students and the variation between the focus groups: some groups engaged in vivid and lengthy discussions, whereas others discussed in a calmer or in a more reserved manner. The discussions were recorded with two tape recorders to ensure quality and transcribed verbatim by the researcher. The interviews, the transcripts, and the coding presented in this article were all performed by the same person. Further detail on the overall research design and data collection procedure is provided 
elsewhere (Author 2016; Author et al. 2016).

\section{Analysis}

The aim of the analysis was to bring forth young people's experiences of school food and school lunch situations through exploring the roles of humour and laughter in their group interaction. Although humour and laughter have particular traits that separate them from one another, they are also closely interconnected and can thus be examined as a joint phenomenon (Watson 2015). On the other hand, while humour provides cues of intentions of the person engaging in humorous behaviour, laughter illustrates the reactions of the intended audience, and the social acceptance or resistance to the initial aims (Meyer, 2000).

In this article, laughter was used as an analytic lead for pinpointing significant data trails for further analysis. As referred, it is acknowledged that not all instances of laughter necessarily mark the appearance of humour, and that humour might represent itself in other ways besides being proceeded by laughter. Nonetheless, laughter was seen as a valid entry point to the data and a way to tune into values and meanings of school food among young people. The analyses consisted of three successive stages, which are described below in more detail. The Atlas.ti program (version 7.5.10) was used throughout the coding process as an aid in classifying and grouping the data.

First, the focus group discussion transcripts (203 pages, Times New Roman font, 12-point font, and 1.5 line spacing) were carefully read through. During this initial reading, all appearances of laughter were marked for further analysis (altogether 265 instances). Based on this stage, it was concluded that the appearance of laughter was connected to not only one form of humorous behaviour, but many, and that a more fine- 
grained classification of the nature of the interaction and of the instances followed by laughter was needed.

Accordingly, in the second stage, a more detailed analytical framework of the nature of utterances preceding laughter was constructed based on prior literature. At this point, and based on the delineation of this article, only those utterances that were specifically connected with school food or school lunch situations were chosen for further analysis (altogether 200 instances). This stage of the qualitative data analysis can be described as typological analysis, in which data is systematically coded according to a predetermined classification, which is generated from theory, common sense and/or research objectives (Hatch 2002). All utterances connected with school food and preceding laughter were then categorized according to this framework (Table 2).

\section{(TABLE 2 HERE)}

The categories presented in Table 2 and their respective definitions were complemented during the coding process. The finalized coding scheme included seven sub-categories, four of which were established based on prior literature (Irony, Sarcasm, Quip, Imitation) and three that were added based on the focus group discussion data (Banter, Ridicule, Non-humour). The delineated data extracts were then carefully re-read and the coding was checked against the complemented typology.

In this, and all the stages of the analysis process that followed, returning to the original audio recordings and listening to the volume and tone of the utterances proved to be a vital part of the interpretive process. In other words, listening to the auditive dimension of the utterance (how something was said) in conjunction with the transcripts (what was said) helped in being able to make distinctions between the presented categories. This insight includes important challenges in reference to securing the 
anonymity of participants and verifying the reliability of analyses, which will be returned to in more detail in the discussion section.

As a part of the second stage of the coding process, and in order to gain a deeper understanding of the aim and audience of utterances preceding laughter, the instances categorized according to the named seven sub-categories were further grouped based on the three-fold classification of the theories of humour (see Table 3). Interpretation was supported by the following theory-driven questions: Who or what is being positioned as the target of humour? Who can be interpreted as the audience of the humorous behavior? What can be interpreted as the aim of the humorous input?

\section{(TABLE 3 HERE)}

In the third and final stage of the coding process the unit of analysis was widened to encompass the nature of the appearing laughter, as well as the interaction that followed each act of laughing. At this point, it was concluded that some utterances and appearances of laughter were difficult to interpret as isolated incidences, and that they seemed to make sense only in reference to a wider trail of interaction. In accordance, the data was grouped as a total of 145 episodes, with the beginning and end of an episode being marked based on a particular topic of discussion. Concurrently, 55 of the altogether 200 episodes includes several utterances followed by laughter, but only one focus of discussion and one theoretical frame of reference, which proved to be important in being able to interpret the isolated appearances of laughter in the same episode.

Analytically, the focus at this third and final stage was directed to the social dynamics of each episode, that is, whether the nature of the appearing laughter and the possible verbal responses following original utterances could be interpreted as 
supporting or opposing the beginning of the episode. The nature of the laughter refers here to the variety (e.g. snickering, giggle, chortles, chuckle, belly laughter, guffaw) and qualities (tone and volume) of laughter in the episodes. Accordingly, attention was paid to the tone and volume of verbal responses as supportive cues for interpreting the nature of the response. Based on this stage, all the episodes were further coded as including either affirmative or hesitant laughter and as including either supporting or opposing verbal response.

Figure 1 provides a visual illustration of the unit of analysis (episode) for this study in its entirety. Numbers 1 to 3 point out how different parts of the episode were emphasised in the above described three stages of the analysis process.

\section{(FIGURE 1 HERE)}

The presented analyses resulted with three themes, which illustrate how humour and laughter functioned for the students as a space for 1) Constructing 'us' versus 'them'; 2) Negotiating social order; and 3) Engaging in fun and safe interaction. Results are interpreted according to the presented theory-based grouping, and mirrored against the social dynamics identified in the third and final stage of the analysis process.

\section{Results}

\section{Constructing 'us' versus 'them'}

In this study, the interpretation of superiority theory encompasses not only finding humour in the misfortune of others, but also laughter following the highlighted superiority of one's own group in comparison to another social group. In the data, highlighting the difference between 'us' and 'them' took place in relation to younger children, the teachers or other adults in the school. The following episode provides an 
example:

Focus group discussion transcripts, group of girls (Coding: quip; superiority theory; affirmative laughter; supporting verbal response)

Linda: 'The truth is, anyway, that the younger [students] eat all kinds of convenience foods more easily because almost anything is good enough for them'. Katja: 'That's right'.

Linda: 'Because they still...their tastes have not been refined to, kind of, high class'.

[snickering; giggling]

As presented in Table 2, the extract above is an illustration of the category 'Quip', which includes clever, witty, or humorous remarks about school food or school lunch situations. In the example, Linda makes an age-based separation between two groups: her own reference group of 9th grade students (15-16-year-olds) and that of younger children, whose tastes for food she describes as having not yet developed to meet the standards of their own group. The tone of the laughter (snickering; giggling) that follows Linda's second statement is somewhat malicious, enforcing the construction of the difference between the named social categories. As interpreted through the framework of the superiority theory (see Table 3), the extract represents younger groups of children as the target of laughter and the age group of Linda and her friends as the audience - the superior group. Through underlining that the younger children have not yet developed the ability to recognize refined and high-class tastes, the episode simultaneously presents the older group as possessing the experience, competence and ability needed to distinguish between unrefined and refined tastes and the skill to appreciate the latter. School food, although not the actual target of the laughter, is referred to in the extract as including ready-made foods and as something that is good enough for the younger age groups, but not for themselves. The girls thus offer the refined tastes of their own group as an explanation and justification for their indirect 
school food criticism. Most importantly, through strengthening the difference between their group and other age groups, the girls strengthen the coherence of and belonging to their immediate social reference group (i.e. their peers). This empirical example is also a demonstration of how humour works in terms of shared assumptions, that is, that school food is not 'good' or 'high class'.

In sum, talking about school lunches was illustrated in the data as a way to strengthen peer group coherence on the one hand and to construct difference to other social groups, such as younger children or the school's adults on the other hand. The simultaneous effect of distancing one group and strengthening the bonds of the immediate reference group were especially strong in examples that targeted a particular social group. Notably, not all episodes in the data included affirmative laughter and supporting verbal response form the part of the other students, as in the episode above, thus highlighting the importance of interpreting humour in context and including also an analysis of the social response to the humorous input.

\section{Negotiating social order}

The term social order refers here to the wider etiquette, rules, norms or manners that are generally accepted in a social setting. In reference to this, discussions of breaking the rules, such as leaving the school premises to buy food from the store or eating food secretly in the hallway resulted many times with hesitant laughter in the other students, which could be interpreted through the framework of the relief theory (see Table 3). Breaking the rules could thus be interpreted as a controversial and ambiguous topic for some of the participants or as something that the students were perhaps hesitant to discuss with the adult researcher in the focus group situation. On the other hand, the use of humour provided also a space for the students to express viewpoints that were in 
contrast with the formal rules, as the following empirical example illustrates:

Focus group discussion transcripts, group of girls (Coding: quip; relief theory; affirmative laughter; supportive verbal response)

Researcher: "So, the picture here [referring to the activating material produced by the students] depicts quite a critical attitude to school lunches. But in addition to this kind of perspective, many also talk about school lunches in a positive manner. In addition, a majority of the students in your school eat in the dining room every day. What do you think is the reason for this contradiction?"

[silence, 4 seconds]

Kerttu: "Because your hungry."

[silence, 4 seconds]

Kerttu: "You're not allowed to leave the school's premises to get food."

Eerika: "Mm. That's true. Especially if you have a long day, then you just have to eat something."

[silence 2 seconds, sniffling]

Iina: "Well, it has happened that it [school food] has been brought from other places, as well." [passive tense]

[a burst of snigger; sniffling]

[silence, 3 seconds]

Kerttu: "Let's not talk about that."

[quiet chuckles]

Iina: "Yeah, don't admit anything."

[snigger; chortles]

[silence 3 seconds]

Researcher: "Where do you go and get it [the food], if you go and get it outside the school's premises?

[silence 3 seconds, silent humming; sniffling]

Kerttu: "Soon this is like played in the teachers' lounge." [uttered while laughing] Iina: "From X [a nearby grocery store]. Or some place, XX [a nearby gas station]."

Kerttu: "Or from home." [uttered whispering]

Iina: "Yeah, or from home."

[silent humming]

In reference to the classification presented in Table 2, this episode provides examples of the category 'Quip'. In the extract, the researcher asks the students for their 
interpretations about the different kinds of attitudes towards school lunches and the popularity of eating in the school dining room in the study school. The responses of the students are hesitant, illustrated especially through the pauses in the trail of discussion. However, the witty remark uttered by Iina produces a burst of laughter in the other students, which through the framework of the relief theory (Table 3) can be interpreted as being a consequence of reduced stress or anxiety. In other words, Iina's witty comment reduces the tension that builds up from the topic of discussion and Kerttu's response ("You're not allowed to leave the school's premises to get food"). Importantly, through the means of humour, the students are able to discuss and reflect upon something that clearly takes place in their everyday life - despite the school's rules forbidding it - thus depicting young people's school lunch practices not only as something that plays out through obedience to adult perspectives, but also through negotiating and potentially challenging the dominant social order. Notably, the young people in this study were typically very aware of the aims and boundaries set by the adults of the school but, as the episode demonstrates, they did not always choose to align with them. Accordingly, the students' perspectives included also aspects that did not seem to fit the adult agenda and that included elements that the students did not always want the teachers to be fully aware of, as Kerttu's comment ("Soon this is like played in the teachers' lounge") demonstrates.

In interpreting this episode, as well as all other data presented in this article, it is important to remember the social context of the interaction: it takes place within the formal school and in a focus group discussion led by an adult moderator. In this way, the episode illustrates also the context-dependency of humour and how estimating what is suitable to do or to discuss and what is not might shift according to the dominant social order in a particular settings. 


\section{Engaging in Fun and Safe Interaction}

Based on the analyses, talking about school lunches in a critical manner portrayed itself many times in these data as a way to bring about laughter in other students. In contrast, stating positive opinions about this theme was typically challenged by other members in the focus group discussion. This underlines school lunch criticism as a socially safe form of behaviour among the students, and potentially also a source of amusement among peers.

Accordingly, instances that seemed to clash with the prominent critical or negative attitude towards school lunch situations could be interpreted through the theoretical framework of the incongruity theory (see Table 3), which seeks to explain laughter in instances that include activities or utterances that clash with existing ideas of how things should be or function. The following extract is an example of a sarcastic remark about the contents of school lunches causing laughter:

Focus group discussion transcripts, group of girls (Coding: sarcasm; incongruity theory; affirmative laughter; no verbal response)

Researcher: 'The majority of the students of this school eat in the dining room every day. Still, it [school food] is referred to in an awfully critical manner. What do you think causes this?'

Henni: 'Well, I think it's sometimes quite well deserved, you know, because the salad can be really shabby so you really don't feel like touching it. Or the bread is really hard or even frozen'.

Niina: 'Yeah, but at the same time, it's possible [that school food is good]. Like today there were potatoes with peels or you know, again, you can always find something good in there also'.

Ella: 'Lucky day'. [in a sour and matter-of-fact tone]

[loud belly laughter; chortles, giggling; chuckles; chuffing]

In the episode, Ella's dryly uttered comment 'Lucky day' is followed by a loud burst of laughter form the other students. Through Ella's comment, the school food is shifted 
from something also including positive aspects (Niina's comment) to the target of impish laughter. From the perspective of school lunch criticism and negative school food talk, it is interesting that the peer group is not as welcoming towards Niina's point that there are always also positive things you can find in the school lunch. Ella's sarcastic comment ('Lucky day') undermines Niina's previous statement, the effect of which is fortified with the laughter that follows.

The following instance is an example of interaction including banter (see Table 1). This instance took place in the same focus group as the data extract above. In the episode, the girls discuss their favourite dishes and one girl challenges another about her preference for a dish made of sliced chicken meat (kanaviillokki):

Focus group discussion transcripts, group of girls (Coding: incongruity theory; banter; affirmative laughter; opposing verbal response)

Niina: 'Or then there's something like a dish made of sliced chicken meat (kanaviillokki), that's like really great, or you know ...'

Henni: 'That's like [snigger] Ella's kanaviillokki. Do you have something to say about kanaviillokki?'

[belly laughter; loud guffaw; snicker]

Ella: 'Kanaviillokki is my favourite sauce'. [with a firm and declarative tone]

In the episode, one of the students (Ella) is being positioned as the primary target of the laughter, although Niina initiates the discussion on the subject and also states that she likes the named dish. The laughter that follows Henni's remark can-through the inconsistency theory-be interpreted as a result of implying inconsistency with the norm of having a critical attitude towards school lunches (i.e. the reference to Ella's favourite chicken sauce dish). Notably, despite the provocative nature of the situation between Henni and the other girls (Niina and Ella), the tone of the laughter that follows is, based on the audio recording, joyous and happy, indicating that the episode can be interpreted as good-humoured and friendly banter instead of negative provocation 
among the girls. From the perspective of food education, however, it is of interest that the instance positions the notion of liking a specific school lunch dish as a source of ridicule. In addition, it is noteworthy that in the earlier example from the same focus group discussion, Ella takes the role of targeting school food through a sarcastic remark, while this episode demonstrates that she clearly also has favourites among school lunch dishes and is not hesitant about stating this in front of her friends.

Overall, the analyses revealed that being able to criticize school lunches in a humorous manner was often a way to amuse fellow students and to gain other's approval. Even those students, such as Ella, who found positive perspectives in school food and were willing and able to defend their opinions against banter from her friends, took part in constructing the negative way of talking about school lunches. In some episodes, being able to find a source for criticism from these themes appeared even as a positive thing worth highlighting. This demonstrates how school food also works as a resource for the students for establishing common ground—a safe topic of playful conversation when other topics may be too risky or personal.

\section{Discussion}

The article explored the role of humour in young people's group interaction in relation to school food and school lunch situations. The overall aim was to explore how collective attitudes towards school food are constructed, enforced and distributed among students, as well as what kinds of issues around school food are considered to be important and worthwhile in the context of their informal peer cultures.

The results support prior notions of the importance of humour and laughter for young people as well as the power of humour to build belonging and coherence among students (Herkman 2001; Hokkanen 2014). However, the results also show how humour 
and laughter functioned for the participants as a space for 1) Constructing 'us' versus 'them'; 2) Negotiating social order; and 3) Engaging in fun and safe interaction. Accordingly, an analysis of humour and laughter revealed how school food and school lunch situations are not a separate part of young people's lives, but rather are tightly intertwined with the social dynamics of the peer group and the sometimes challenging position young people occupy when trying to influence existing power relations.

In line with previous research (e.g. Persson-Osowski 2012), a critical attitude towards school food seemed to be the collective norm among the participants, and deviance from this norm could bring about a negative social reaction from peers. This remained so even in cases in which students found positive aspects in the school food or had personal favourites. Placing school food as a target or a source of humour thus presented itself as a way to avoid social exclusion or to gain attention from peers. In addition, humour functioned as a way to challenge authority and to address themes that did not easily fit the adult agenda. Importantly, the results further demonstrate how these data are connected to the particular social norms of the focus group discussions as a social setting: the interaction reflects not only attitudes in reference to school food, but also the social dynamics in the specific context of an adult-led focus group discussion arranged at school and during the school day.

The trustworthiness of the coding presented in this article has been approached though striving towards transparent and detailed description of the analysis process (Silverman, 1993; Hatch, 2002). During the analyses, the auditive dimension of the interaction proved to be a vital aspect in being able to interpret the roles of humour and laughter in these data. This highlights that experience and meaning are not only about langue and text (i.e. what is said), but that how something is said might shift the meanings of utterances in context. Although it is a challenge to capture this dimension 
in text-based empirical examples, providing samples of the original audio recordings would be equally difficult, because of issues connected with protecting the anonymity of the participants. While analytical triangulation (i.e. cross-checking coding by several researchers) has not been possible in the present study, it might be a justifiable procedure in future research to enhance the validity of interpretations.

Finally, it is important to note that the present article focused especially on modes of verbal interaction and was based upon the researcher's interpretations of the roles of humour and laughter, which should be taken as limitations of the presented analyses. Due to the ambiguous nature of humour, research designs also enabling young people's own interpretations of their interactions including laughter, such as stimulated recall methods, could prove to be beneficial in the future. Furthermore, entering and delineating data based on instances that include laughter might not be able to grasp humour that manifests itself through other forms of interaction (e.g., gestures and facial expressions). The category non-humour (see Table 2) also demonstrates that a delineation of data based on appearances of laughter might result with instances that cannot unambiguously be interpreted as being connected to humourous intentions (see Meyer, 2000). Further research on the different forms and roles of humour and laughter is needed in order to be able to conceptualise the multiple facets of this phenomenon. In this respect, different applications of video research methods or conversation analysis techniques could be useful, although there might also be other approaches to consider.

\section{Conclusions}

An analysis of young people's group interaction and the roles of humour and laughter in relation to school food and school lunch situations reveals how humour has the power to divide and connect social groups, to enforce or contest social norms, and to provide 
young people spaces for fun and enjoyable interaction. As entangled with the previous, school food and school lunch situations were often referred to in the data in a negative or pointedly critical manner. This has two implications from the particular perspective of co-developing school lunch situations together with youth: 1) If school food actually tastes bad or is of poor quality, it should be developed accordingly and youth critiques about it should not be shut down or bypassed. 2) However, if humour and laughter has other aims from the perspective of youth peer cultures, it is - for an adult working with young people - beneficial to be conscious of these meanings and connotations. In reference to both presented points, an open, realistic and constructive discussion of school meals is of importance especially within the current shift towards promoting students' participation and agency in school meal development (Author, 2016). Finally, future studies on the roles of humour and laughter in young people's group interaction might benefit from, for example, using video methods as a way of capturing facial expressions and gestures, and from collecting data from also other social settings besides focus group discussions and the formal school context.

\section{Notes}

1 Finnish municipalities are legally bound to serve pupils a tax-paid meal every school day. The meal should be appropriately organized and nutritionally balanced. According to the National Nutrition Council's school meal guidelines, the meal should provide $1 / 3$ of the daily energy intake. The lunch is typically a hot meal, such as a casserole dish or a soup, served with vegetables and/or salad, bread, spread and beverages. Many schools provide pupils an additional breakfast and/or snack service, which is subject to charge.

Acknowledgements: My sincere thanks to Professor N.N. and doctoral researcher N.N. for their valuable comments on this article.

\section{References}

Author, 2016; Author et al. 2016. (2 references have been removed from the manuscript 
to ensure anonymity)

Atkinson, R. 1993. 'Humour in Philosophy.' In Humour and History, edited by K. Cameron, 10-20. Oxford: Intellect.

Bahr Bugge, A. 2010. 'Young People's School Food Styles: Naughty or Nice?' Young 18(2): 223-243. doi: 10.1177/110330881001800206

Bergson, H. 1899. Le Rire: essai sur la signification du comique. Paris.

Billig, M. 2001. 'Humour and Embarrassment Limits of 'Nice-Guy' Theories of Social Life.' Theory, Culture and Society, 18(5): 23-43. doi: 10.1177/02632760122051959

Billig, M. 2005. 'Laughter and Ridicule. Towards a Social Critique of Humour.' London, Thousand Oaks and New Delhi: Sage Publications Ldt.

Cameron, K. 1993. 'Humour in Philosophy.' In Humour and History, edited by K. Cameron, 5-9. Oxford: Intellect.

Cameron, E. L., Fox, J. D., Anderson, M. S., and Cameron, C. A. 2010. 'Resilient Youths Use Humor to Enhance Socio-emotional Functioning during a Day in the Life.' Journal of Adolescent Research 25(5): 716-742. doi: 10.1177/0743558410366595

Corsaro, W. 2005. The Sociology of Childhood. 2nd edition. Bloomington: Indiana University.

FNBE (Finnish National Board of Education) 2014. 'School Meals in Finland.' Accessed June 8, 2016.

http://www.oph.fi/download/155535_School_meals_in_finland.pdf

Freud, S. 1905; 1981. Jokes and their Relation to the Unconscious (Translated by James 
Strachey; in collaboration with Anna Freud; assisted by Alix Strachey and Alan Tyson). London: The Hogarth Press and The Institute of Psycho-analysis.

Gordon, T., Lahelma, E., Hynninen, P., Metso, T., Palmu, T., and Tolonen, T. 1999. 'Learning the routines. Professionalisation of newcomers to secondary school.' International Journal of Qualitative Studies in Education 12(6): 689-705. doi: $10.1080 / 095183999235836$

Hatch, A. 2002. Doing Qualitative Research in Education Settings. State University of New York press, Albany, NY.

Herkman, J. 2001. 'Huumorin ja vallan keskeneräinen kysymys populaarin kokemuksen jäljillä' ['The unfinished question between humour and power tracing the popular experience']. In Populaarin lumo-mediat ja arki, edited by A. Koivunen, S. Paasonen and M. Pajala, 368-384. Series A of the University of Turku Department of Arts studies no 46.

Hobbes, T. 1690. Leviathan. Amstelodami.

Hokkanen, L. 2014. 'Sairaan hauskaa! Nuorten kasvatuksellinen kapina folkloressa' ['Sickly Fun! Young People's Educational Rebellion in Folklore']. Kasvatus ja Aika, $3 / 2014$.

Hutcheon, L. 1995. Irony's Edge: the Theory and Politics of Irony. New York: Routledge.

Kant, I. 1982. The Critique of Judgement (Translated by James Creed Meredith). New York: Oxford University Press.

Korkiamäki, R. 2011. 'Support and Control among "Friends" and "Special Friends": 
Peer Groups' Social Resources as Emotional and Moral Performances amidst Teenagers.' Children and Society 25(2): 104-114. doi: 10.1111/j.1099-

0860.2009.00262.x

Lee, J. and Katz, A. 1998. 'The Differential Role of Ridicule in Sarcasm and Irony.' Metaphor and Symbol, 13(1): 1-15, doi: 10.1207/s15327868ms1301_1

Meyer, J. 2000. 'Humor as a Double-Edged Sword: Four Functions of Humor in Communication.' Communication Theory, 10(3): 310-331. doi: 10.1111/j.14682885.2000.tb00194.x

Neely, E., Walton, M., and Stephens, C. 2014. 'Young People's Food Practices and Social Relationships. A Thematic Synthesis.' Appetite 82(1): 50-60.

Palmqvist, R., and Santavirta, N. 2006. 'What Friends Are For: The Relationships Between Body Image, Substance Use, and Peer Influence Among Finnish Adolescents.' Journal of Youth and Adolescence 35(2): 203-217. doi: 10.1007/s10964-005-9017-2 Persson-Osowski, C. 2012. The Swedish School Meal as a Public Meal: Collective Thinking, Actions and Meal Patterns. Doctoral dissertation (Articles). University of Uppsala.

POPS. 2014. Perusopetuksen opetussuunnitelman perusteet [The Basics of the National Curriculum]. Accessed June 23, 2016.

http://www.oph.fi/download/163777_perusopetuksen_opetussuunnitelman_perusteet_2 014.pdf

Schopenhauer, A. 1909. The World as Will and Idea (Translated by R. B. Haldane and J. Kemp). 7th ed. London: Kegan Paul, Trench, Trübner \& Co. 
Sciama, J. 2016. Humour, comedy and laughter: obscenities, paradoxes, insights and the renewal of life. New York: Berghahn books.

Silverman, D. 1993. Interpreting Qualitative Data. London: Sage.

Sørensen, M. J. 2015. Humorous Political Stunts. Nonviolent Political Challenges to Power. Sparsnäs: Irene Publishing.

Valve, H. and Pelkonen, R. 2013. 'Onko semmoista vaihtoehtoa, että ei kiinnosta? Kuluttajat, uudet teknologiat ja ryhmäkeskustelujen kurittomuus' ['Is Not Being Interested an Option? Consumers, New Technologies and Undisciplinarity in Focus Group Discussions']. In Kulutuksen kuvat, edited by M., Lammi, J. Mäkelä and V. Mustonen, 168-185. Kuluttajatutkimuskeskuksen vuosikirja 2013, Kuluttajatutkimuskeskuksen vuosikirjoja 8.

Virtanen, J. 2003. 'Vitsi tutkimuskohteena. Huumorintutkimuksen jaakopinpainia' ['A Joke as the Target of Research. The Jacob's Wrestle of Humour Research']. Elore 1/2003. Joensuu: Suomen Kansantietouden Tutkijain Seura ry.

Watson, C. 2015. 'A Sociologist Walks into a Bar (and Other Academic Challenges): Towards a Methodology of Humour.' Sociology 49: 407-421. doi:

$10.1177 / 0038038513516694$

Q

Q

(4) 